\title{
Entre Mussolini e Plínio Salgado: o Fascismo italiano, o Integralismo e o problema dos descendentes de italianos no Brasil*
}

\author{
João Fábio Bertonha \\ Universidade Estadual de Maringá
}

\section{RESUMO}

O objetivo desse artigo é avaliar o relacionamento entre o Fascismo italiano e o Integralismo brasileiro. O texto tenta mostrar a importância do Fascismo de Mussolini na formação e construção da ideologia integralista, assim como na formação de sua base social. Nesse sentido, o texto foca com especial ênfase a questão dos brasileiros filhos de italianos, público privilegiado tanto da propaganda fascista como da integralista.

Palavras-chave: Fascismo; Integralismo; italianos.

\begin{abstract}
The purpose of this article is to evaluate the relationship between Italian Fascism and Brazilian Integralism. The text seeks to show the very important contribution of Mussolini's movement to the formation and construction of Brazilian Integralist ideology and popularity. The question of the "oriundi" (Brazilians of Italian heritage) and their relationship with Fascism and Integralism is especially stressed. Keywords: Fascism; Integralism; italians.
\end{abstract}


A partir dos anos 70, o Integralismo e o pensamento autoritário nacional como um todo foram objeto de inusitado interesse por parte dos cientistas sociais brasileiros. Dentro dos estudos sobre a Ação Integralista Brasileira (AIB), porém, a questão que mais chamou a atenção dos autores foi a da sua natureza e das condições que propiciaram o seu surgimento. Emergiram daí diversas proposições: seria o Integralismo simples reflexo de uma ideologia européia? Constituiria algo distinto do Fascismo europeu em face das condições diversas do Brasil?

Esse debate, que consumiu o esforço intelectual de inúmeros historiadores e cientistas políticos brasileiros no decorrer dos anos $70^{1}$, permitiu um grande avanço nos nossos conhecimentos sobre o movimento ao abordar temas como a base social do Integralismo, o contexto socioeconômico de onde ele surgiu, as influências da ideologia fascista européia (basicamente as do Fascismo italiano, do Nazismo alemão e das correntes fascistas portuguesas) na sua constituição em suas especificidades próprias, etc.

Se pensarmos especificadamente na questão do caráter mimético do Integralismo, contudo, é possível verificar certas lacunas nos esquemas interpretativos elaborados pela historiografia. De fato, identificar certas características (base social, ideologia, contexto econômico) do Integralismo e compará-las com as 86 suas equivalentes nos países do Fascismo clássico é, sem dúvida, algo fundamental para definir o caráter da AIB. Ainda assim, o trabalho com outras variáveis pode, a nosso ver, levantar elementos tão ou mais relevantes para a questão quanto à comparação pontual de elementos do Integralismo e dos fascismos europeus.

O que queremos deixar claro, assim, é que não pretendemos, neste ensaio, retomar a comparação entre o movimento dos camisas-verdes e dos fascismos europeus, mas sim visualizar certos laços de relacionamento e solidariedade (não só, como veremos, ideológicos) do Integralismo com o Fascismo italiano, que nos permitirão não só levantar novos elementos para a discussão de seu caráter, como ampliar nosso conhecimento das relações da ideologia fascista com a política externa do Estado italiano no entre-guerras, e dos próprios meandros do relacionamento do Brasil com a Itália no período. Nesse sentido, o primeiro aspecto a ser abordado é o das relações entre o governo fascista italiano e a Ação Integralista Brasileira, que foram realmente intensas².

As primeiras notas sobre a formação da AIB foram enviadas a Roma pelo cônsul de São Paulo, Serafino Mazzolini, em 1931. Mazzolini foi transferido, porém, para Montevidéu em 1932, e os cônsules e embaixadores subseqüentes (até 1936) só fizeram análises superficiais sobre o Integralismo. Tais análises preocupavam-se, principalmente, em identificar os pontos comuns da ação dos integra- 
listas com a do Fascismo italiano e escondiam várias preocupações: o nacionalismo integralista, que parecia ser uma fonte de conflito com a Itália; a crescente influência nazista no movimento e conseqüente perda de prestigio do Fascismo, etc.

A partir de 1936, a atitude italiana diante da AIB mudou e esta passou a ser vista como movimento de importância e analisada com maior positividade. Tal mudança de política foi devida ao evidente crescimento do poder político do Integralismo, maior atenção do governo italiano e a agudeza e capacidade de observação do encarregado de negócios italiano Menzinger, que tomou conta dos assuntos da Embaixada a partir de meados de 1936.

O documento que marcou essa mudança de postura é um telegrama do conde Ciano aos cônsules e à Embaixada no Brasil em outubro de 1936, pedindo informações sobre o Integralismo e a conveniência em apoiá-lo. As respostas dos cônsules desaconselharam o apoio por temor de choque de nacionalismos e por uma certa desconfiança residual com a A1B. Já a Embaixada do Rio de Janeiro, sob a responsabilidade de Menzinger, propôs ajudar o Integralismo através de subsídios e da transferência do apoio dos ítalo-brasileiros sob a influência de Roma para o movimento.

OMinistero degli Affari Esteri aceitou as propostas de Menzinger e resolveu acreditar nas informações colhidas de que a Ação Integralista estava tendo penetração real na sociedade brasileira, e de que se poderia tirar o movimento da órbita nazista para a fascista. Além disso, o governo italiano enviou um emissário ao País, o dr. Gomes, para estudar o Integralismo, e este se impressionou com o movimento, defendendo o apoio ao mesmo para facilitar o seu controle, aumentar a influência italiana na política brasileira e, no limite, levar o Brasil para a órbita do Eixo. Com isso, um subsídio financeiro passou a ser transferido regularmente dos cofres italianos para os integralistas ${ }^{3}$, apoiando o seu esforço para se tornar um movimento político organizado.

Após a instauração do Estado Novo, porém, a Itália desestimulou os integralistas a lutar contra Vargas, instando-os a colaborar com o novo regime. Não é de estranhar essa mudança de atitude italiana: o novo governo era simpático a Roma; Vargas tinha, nos altos círculos fascistas, um juízo mais alto do que Plínio Salgado, e o Brasil, sob o Estado Novo varguista, parecia se fascistizar com rapidez. Razão para o afastamento do governo italiano da AIB, recusa de fornecimento de armas e cancelamento dos subsídios financeiros em 1938.

O embaixador Lojacono era de opinião que o Integralismo ainda teria algum papel na história do Brasil e que seria útil continuar fazendo o jogo duplo de boas relações tanto com Salgado como com Vargas, mas Roma, satisfeita com o novo governo brasileiro e certa agora de que o Integralismo não tinha mais fu- 
turo político, confirmou o cancelamento dos apoios em 1938, mesmo ano em que os integralistas tentaram dar um golpe de Estado (quando pediram, aliás, ajuda italiana para o mesmo e asilo político quando ele falhou) e foram dispersos e reprimidos pelo governo. Um fim melancólico para uma relação que, apesar de tudo, foi amigável a maior parte do tempo.

As boas relações entre a AIB e o governo fascista italiano não se limitaram, porém, ao fornecimento de fundos por parte dos italianos. Elas foram muito mais complexas e intrincadas do que parecem à primeira vista e, como veículo para esse íntimo relacionamento, foram fundamentais as coletividades italianas presentes no Brasil e a estrutura de catequese montada pelo governo fascista para atingi-las.

Essa faceta do movimento integralista é muito reveladora ao nos permitir levantar vários elementos interessantes sobre sua constituição e caráter. De fato, o debate a respeito do caráter fascista do Integralismo pode ser muito enriquecido por essa visão das suas intensas relações com o Fascismo italiano. Ao mesmo tempo, esse relacionamento é a chave para entendermos algumas das influências que as atividades italianas trouxeram à cena política brasileira. Nesse sentido, examinemos, em primeiro lugar, a questão do Fascismo italiano como fonte de inspiração para os Fascismos nacionais e os caminhos pelos quais pedaços da expe88 riência fascista italiana foram transplantados para o corpo do movimento integralista.

Infelizmente, os primórdios do Fascismo no Brasil são ainda pouco estudados. Não resta dúvida, porém, de que os primeiros passos do Fascismo no Brasil foram, em boa parte, inspirados pelo Fascismo italiano e por sua atividade no Brasil. De fato, já em 1922 surgiu, com clara inspiração fascista, a Legião Cruzeiro do Sul. Os movimentos posteriores, como o Partido Nacional Fascista/Ação Social Brasileira de J.. Fabrino, a Legião Cearense do Trabalho, o Partido Nacional Sindicalista de Olbiano de Mello, o Partido Fascista Brasileiro, a Ação Imperial Patrianovista Brasileira e a Legião 3 de Outubro também tiveram, ao lado de um enraizamento no clima intelectual brasileiro, uma inspiração - que era expressa diretamente em seus manifestos e que, obviamente, variou de movimento para movimento - na Itália de Mussolini. Nesse ponto, concordamos com Carone ${ }^{4}$ quando ele identifica, no Brasil dos anos 20, duas correntes de pensamento e ação de extrema direita que se interligavam: a fascista italiana e as pequenas tentativas de criação de um Fascismo indígena. A influência italiana nesse momento estava, pois, mais que clara.

Essa situação de inspiração num referencial externo foi não apenas mantida, como ampliada no pós 1932, período em que surgiu a Ação Integralista Brasileira. Não era esse certamente o momento para rediscutir em profundida- 
de as influências do Fascismo italiano na ideologia integralista ou fazer comparações pontuais entre elas. Era impossível não reconhecer no Integralismo, porém, uma série de influências do Fascismo italiano e também de outros movimentos fascistas europeus. Essas influências passavam especialmente pelo campo ideológico, como a doutrina corporativa, a descrença na democracia, a priorização do Estado em relação à sociedade, etc., mas também se manifestavam em itens aparentemente secundários, como a mística e a simbologia, em que eram evidentes as influências do Fascismo italiano na mitologia do líder, na coreografia das grandes manifestações, na doutrinação da juventude (na qual a organização dos "plinianos" se assemelhava notavelmente à dos "balilas" italianos), etc.

Mais importante do que o reconhecimento dessa influência, contudo, era verificar os canais concretos pelos quais elementos do organismo fascista italiano passaram ao seu equivalente brasileiro e influenciaram seu caráter e sua constituição.

Dentre esses canais, sobressaíram-se a coletividade italiana e os órgãos fascistas em ação no Brasil, especialmente os de São Paulo. De fato, foi através da Embaixada italiana e dos órgãos da colônia italiana que se criou um fluxo não só de apoio institucional entre o Integralismo e o governo de Mussolini (como já comentado), mas também de influências intelectuais ${ }^{5}$ e políticas que foram relevantes para a difusão de idéias de extrema direita no País e para a própria definição do caráter do movimento. Isso é evidente em líderes como Miguel Reale, que era de origem italiana e estudou em escolas italianas de São Paulo, ${ }^{6}$ e também em Plínio Salgado.

Plínio Salgado mantinha, de fato, colaboração intensa com os órgãos do Fascismo italiano em São Paulo e, apesar dessa colaboração ser até hoje desconhecida, ela foi marcante. Realmente, ele não só editou, junto com Ferrucio Rubbiani (conhecido intelectual fascista de São Paulo) a publicação Rivista Latina nos anos $30^{7}$, como participou em posição de destaque, por exemplo, da "Saudação a Roma", cerimônia promovida pelo Consulado italiano em 25/4/1932, e escreveu em revistas como Hierarchia, em que não só se copiava o título do órgão oficial do Fascismo italiano, como se sucediam artigos laudatórios a este, retratos de Mussolini, etc.

Um outro indício nesse sentido pode ser encontrado no relatório do Consulado Geral dos Estados Unidos em São Paulo ao Departamento de Estado de 19/7/1937, no qual se informava a realização de um grande desfile integralista na Avenida Paulista, e que Plínio Salgado tinha passado os milicianos integralistas em revista a partir da sacada da residência de ninguém menos que Angelo Poci, diretor do jornal fascista paulistano Fanfulla e conhecido fascista italiano em ação no Estado. No mesmo ano, aliás, Plínio Salgado participou da comemora- 
ção do "Natal de Roma" no Circolo Italiano Carlo del Prete em São Paulo, onde fez uma palestra sobre Roma e o Fascismo, "instrumento de redenção dos povos", e recebeu calorosamente o hierarca fascista Luigi Federzoni, em visita ao Brasil ${ }^{8}$.

Vemos, assim, que o relacionamento de Salgado com o Fascismo italiano em São Paulo era tão intenso que não surpreende que um observador da época tenha escrito que:

O fato de que a Itália tomou o lugar da França encontra sua razão no desenvolvimento político do Estado italiano desde 1922. Plínio Salgado conhecia a experiência fascista porque em São Paulo, onde morava, milhares de italianos guardaram a sua nacionalidade e são adeptos entusiastas de Mussolini. Já formavam um grupo importante que tem o seu jornal e com o qual Plínio Salgado mantém relação há longo tempo. ${ }^{9}$

Os sinais de colaboração de Miguel Reale e de Plínio Salgado com os órgãos do governo fascista italiano em São Paulo são, portanto, conclusivos e nos ajudam a ver um dos caminhos concretos pelos quais o Fascismo italiano influenciou o pensamento e a prática política integralista.

Uma relação íntima em vários aspectos e de solidariedade ideológica, e alguns dos caminhos concretos pelos quais elas se deram são, pois, evidentes, e revelam aspectos desconhecidos da história da $\mathrm{A} 1 \mathrm{~B}$ e da própria política italiana e brasileira no período, aspectos estes que ressaltam como os dois movimentos se viam como semelhantes, trocavam apoio direto e experiências entre si através do canal concreto dos órgãos diplomáticos e da colônia e também de outras organizações (como a Igreja Católica), e que as aproximações entre os dois foram realmente mais fortes do que as divergências.

Os aspectos mais curiosos da relação entre os dois movimentos aparecem, porém, ao discutirmos a questão da base social, quando os conflitos e disputas entre fascistas e integralistas se sucediam, ao mesmo tempo em que jamais cessava a colaboração entre ambos. Dentro dessa dinâmica de colaboração/rivalidade entre os dois movimentos em nível de base, o grande campo de batalha era a comunidade italiana local e, especialmente, os brasileiros descendentes de italianos, que eram disputados por ambos os movimentos e são o foco central de nossa análise.

Aparentemente, o choque de nacionalismos entre a Ação Integralista Brasileira, desejosa de converter a comunidade ítalo-brasileira num grupo de pessoas que ignorasse sua primeira parte do hífen e os fascistas italianos em ação no Brasil, lutando para manter a italianidade dessas mesmas pessoas, devia ser insuperável e levar a conflitos inadministráveis. Aparentemente prenunciando isto, 
Plínio Salgado escreveu várias vezes, em seu famoso romance de 1926, O Estrangeiro, contra o esforço fascista de querer manter os ítalo-brasileiros ligados à Itália e chegou a colocar um de seus personagens no papel do nacionalista brasileiro que, muito simbolicamente, assassinava os papagaios de um italiano que só cantavam a Giovinezza (o hino fascista) em lugar do hino nacional brasilei$\mathrm{ro}^{10} .0$ conflito parecia inevitável.

Do lado italiano, essas preocupações também existiam. Em 1935, por exemplo, o vice-cônsul italiano em Florianópolis, Guido Zecchin, escreveu ao Ministério das Relações Exteriores italiano:

Um novo inimigo da existência dos fasci é o Integralismo que, embora descendendo mais ou menos legitimamente do Fascismo, faz continuamente prosélitos entre os nossos compatriotas e, infelizmente, rouba nossos melhores elementos.

$\mathrm{Na}$ mesma época, o embaixador Cantalupo também se manifestava no mesmo tom:

Eu não dei até agora um verdadeiro apoio ao Integralismo, pois não acredito que uma tal política seria útil para os nossos interesses no Brasil; de fato, se, por hipótese, os princípios patrióticos do movimento integralista fossem aplicados, não seria possível para a Itália defender e difundir entre seus compatriotas e seus descendentes o nosso idioma, com a criação de dezenas e dezenas de escolas, com a organização de Institutos Ginasiais, de Casas de Itália com a difusão de jornais em idioma italiano, etc., o que venho fazendo de dois anos para cá com confortante e sempre maior sucesso. Os nacionalismos elidem-se. ${ }^{11}$

Como vimos, porém, as contradições Fascismo/Integralismo não foram tão violentas assim ${ }^{12}$. No campo da base social não foi diferente, com vários descendentes de italianos presentes não só na estrutura de propaganda, como também na cúpula da A1B. Além disso, casos de brasileiros descendentes ou não-descendentes de italianos, como o comendador Antônio de Pompeu Camargo (que foi chefe do Dopolavoro da Mooca e Secretário de Finanças do Integralismo), circulando entre Fascismo e Integralismo não parecem ter sido incomuns. Também o emissário do Integralismo à Itália em 1938, o dr. Colpi, era italiano e de longa militância nas fileiras do fascio ${ }^{13}$.

Mesmo quando saímos das lideranças e tentamos nos aprofundar no mais obscuro mundo das bases dos movimentos, há alguns indícios de uma certa fluidez entre os militantes fascistas e integralistas. De fato, há casos registrados de simples militantes integralistas que se relacionavam intimamente tanto com seus equivalentes fascistas ${ }^{14}$ como com os órgãos do governo fascista em São Paulo ${ }^{15}$. Existem também sinais de cruzamento das máquinas de propaganda dos dois 
grupos ${ }^{16}$ e registros de reuniões integralistas acontecendo nas sedes das associações italianas fascistizadas ${ }^{17}$. Nesse sentido, um velho italiano chegou a afirmar que:

Eu era italiano e fascista. Achava que Mussolini era um grande homem que governou a Pátria e fez muito por ela. Os movimentos de antes da guerra eram autorizados pelo governo brasileiro. Aqui em Rio Claro marchavam juntos os fascistas de camisas pretas e os integralistas de camisas verdes. ${ }^{18}$

Vê-se, assim, que o tradicional conflito vivido entre os movimentos fascistas (desejo de diferenciação/choque de nacionalismos e a vontade de demonstrar solidariedade ideológica ${ }^{19}$ ) parecem ter sido superados, no caso das relações entre a AIB e o Fascismo de Mussolini, sem grandes dificuldades ${ }^{20}$, ampliando o relacionamento entre ambos, gerando uma intensa solidariedade ideológica ${ }^{21} \mathrm{e}$ dando mais força ao Integralismo na política brasileira. Claro que não havia absoluta convergência de opiniões entre eles e nem uma unificação total de políticas. Na realidade, porém, os brasileiros (descendentes de italianos ou não) simpáticos a Mussolini e a Plínio Salgado nunca tiveram que fazer a escolha "Integralismo ou Fascismo". Eles só foram induzidos a uma escolha semelhante no período da II Guerra Mundial, quando tiveram que escolher entre Brasil e Itália e optaram maciçamente pelo primeiro. Nesse período, porém, a AIB já estava morta e a dimensão política dessa escolha se perdeu.

Resolvemos então todos os nossos problemas confirmando a permeabilidade entre fascistas e integralistas e reforçando, desse modo, o nosso propósito de identificar as ligações entre ambos? Gostaríamos que fosse assim, mas uma análise mais cuidadosa dos dados empíricos sobre a questão revelam outros problemas, que também devemos enfrentar nesse balanço que estamos fazendo das relações entre o Fascismo italiano e o Integralismo.

As informações disponíveis sobre o Integralismo hoje em dia confirmam que ele teve uma sólida participação da comunidade de origem alemã e também da italiana. De fato, segundo os trabalhos de Hélgio Trindade, 16 por cento dos militantes integralistas de todo o país tinham origem italiana, o que superava largamente a proporção de italianos e filhos de italianos na população nacional.

Em alguns núcleos (especialmente em São Paulo e no Rio Grande do Sul), porém, essa situação de presença maciça de descendentes de imigrantes era ainda mais pronunciada. No núcleo integralista de Rio Claro/SP, por exemplo, o livro de atas revela que, de um total de 197 inscritos em todos os níveis, 72 (36\%) tinham sobrenome italiano e $21\left(10^{\circ}\right.$ o) tinham sobrenome alemão. O mesmo se repete na região de Baurue na seção de Capivari/SP, onde, dos 12 camisas ver- 
des do núcleo local, nada menos que sete eram de origem italiana, o que é revelador.

Também as listas de integralistas presos pelo DOPS paulista em 1938 e a documentação de inúmeras células integralistas do interior do Estado apreendidas pela polícia estão recheadas de sobrenomes italianos. Os livros e jornais publicados pelo governo italiano na época também não se cansavam de destacar o grande número de filhos de italianos na AIB. Os cálculos fascistas são certamente exagerados, mas é inegável que os descendentes de italianos tinham grande participação nas hostes integralistas (muito especialmente em São Paulo e Rio Grande do Sul, mas provavelmente também no resto do país), tanto que boa parte dos integralistas mortos em brigas de rua com os antifascistas (como Nicola Rosica, Alberto Secchini, Amedeo Santini e outros) era de origem italiana

Uma quantificação precisa dessa participação de italianos no Integralismo como um todo é dificultada pela escassez de fontes, mas devia girar em torno de muitas dezenas de milhares de militantes, especialmente em São Paulo, Rio Grande do Sul e Espírito Santo, e um número muito maior de simpatizantes e eleitores.

Sabemos hoje também que o Integralismo foi - basicamente e malgrado algumas especificidades regionais - um movimento de classe média, e que foram os italianos deste grupo que mais responderam ao apelo integralista. Com isso, poderíamos concluir que os ítalos que realmente aderiram à AIB eram basicamente de classe média e que o fizeram única e exclusivamente como uma opção política derivada das contradições e necessidades do momento, sem que qualquer variável étnica estivesse presente.

Essa hipótese é muito confortável, mas esbarra em outras informações que confirmam que os italianos que de maneira efetiva militavam nos órgãos do Partido Fascista em São Paulo e no Brasil como um todo, ou seja, os realmente conquistados pelo Fascismo, também eram principalmente de classe média, o que nos indica que deve existir algo mais que ajude a explicar essa curiosa divisão da pequena burguesia de origem italiana de São Paulo entre Fascismo e Integralismo.

Outro ponto curioso a ser examinado é a ausência de contatos entre a poderosa burguesia industrial italiana de São Paulo e o Integralismo. Mesmo apoiando com fervor o Fascismo italiano, e mesmo sendo esse apoio em boa parte de caráter político, de firme adesão à ideologia fascista, a burguesia italiana de São Paulo parece ter recusado os pedidos de ajuda da AIB, o que causava irritação nos círculos integralistas:

Nos primeiros tempos, os dirigentes da Ação Integralista procuraram obter das empresas industriais de São Paulo a necessária ajuda e alento, pois mesmo sendo 
movidos por entusiásticos propósitos, faltava-lhe uma base financeira para iniciar o movimento com a necessária intensidade. Infelizmente, não foram levados a sério pelos graúdos da coletividade italiana, particularmente pelos filhos de nossos capitalistas que, valendo-se da qualidade de cidadãos brasileiros, teriam podido manter e, se fosse o caso, forçar as orientações do novo partido acerca do Fascismo. ${ }^{22}$

Angelo Trento ressalta, em vários de seus trabalhos, que a burguesia italiana de São Paulo agiu, ao recusar o Integralismo, em defesa de seus interesses e em sintonia com as classes dominantes locais, que não veriam no Integralismo um sério candidato ao sucesso político e preferiram optar pela solução varguista. Isto é perfeitamente aceitável, mas novamente parece haver um "algo mais" que ajude a explicar essa situação.

Esse "algo mais" parece ser a questão étnica e/ou geracional. De fato, essa burguesia italiana a que nos referimos era constituída majoritariamente de italianos natos; a maior parte dos presentes nas cerimônias fascistas era de italianos natos e foram os descendentes de italianos que mais aderiram à Ação Integralista. Isto aparece tão claramente na documentação de época que a Embaixada italiana chegou a chamar essa situação de "conflito de gerações":

Os italianos, especialmente aqueles imigrados há muito tempo, estão envolvidos nas facções dos velhos partidos e não mostram compreender o Integralismo mesmo quando são inscritos ou simpatizantes do Fascio. Os seus filhos, por outro lado, seja porque tenham estudado na Itália e trazido consigo a nostalgia da Camisa negra, seja porque sentem haver encontrado finalmente no Brasil o ideal condutor que antes a juventude não podia encontrar, são todos integralistas. Entre as duas gerações de italianos, a velha e a nova, há, portanto uma fratura que pode também, no período eleitoral, dar lugar a atritos e conflitos, mas que, para os efeitos de nossa ação de apoio ao Integralismo, representa somente uma desvantagem local, acidental e não geral ${ }^{23}$

Com isso, é possível concluir que, ao lado das preocupações de ordem política e de classe que levaram as elites e as classes médias aos caminhos da direita, havia uma variável étnica que prendia os italianos natos (mais sujeitos ao lado nacionalista da propaganda de Roma) ao Fascismo, e os descendentes, mais abrasileirados e aculturados e desejosos, em muitos casos, de se afirmarem e de serem aceitos como brasileiros, ao Integralismo.

Nesse ponto, é básico recordar reflexões de Renè Gertz ${ }^{24}$, em que ele propõe, com razão, que não é possível entender a forte penetração do Integralismo nas zonas de colonização alemã ou italiana do Brasil pensando apenas na questão étnica, e que questões como a inserção política e social dos descendentes de imigrantes devem ser abordadas. 
Estamos de acordo com Gertz. Há, no caso dos italianos de São Paulo e também de outros Estados, mais a ser considerado do que simplesmente a etnia, e criar explicações somente a partir de pressupostos étnicos que não absorvem a diferenciação social interna às colônias e as lutas de classe é algo realmente problemático:

De fato, acreditamos, como já explicitado, que o contexto e as lutas sociais do período também são fundamentais para entender a firme adesão da burguesia e das classes médias de origem italiana de São Paulo às idéias de direita. Parece-nos, porém, que a questão étnica não pode ser esquecida. Seria difícil, sem dúvida, aceitar a hipótese de que os filhos de italianos só se ligaram ao Integralismo pela sua origem étnica. A questão da origem étnica e da busca de identidade ("italiana" ou "brasileira") nos ajuda a entender, porém, a polaridade Fascismo/Integralismo entre os italianos e seus filhos. É assim que entendemos o termo "fator étnico" e é só assim, interagindo com o mundo da política e com questões de classe ${ }^{25}$, que ele pode ser útil.

Claro que essa divisão que fizemos não pode ser vista de forma rígida (ainda mais levando-se em conta a fluidez da militância fascista e integralista que identificamos antes) e que as relações entre os dois movimentos foram realmente complexas, mas é evidente que o contexto político nacional e a ferrenha propaganda do regime de Mussolini (da ideologia fascista e do nacionalismo italiano) atraiu boa parte dos italianos (como a burguesia industrial e parte da classe média) à militância direta nas hostes dos fascios, enquanto um clima geral e difuso de apoio ao Fascismo atingiu (malgrado a atuação dos antifascistas brasileiros e italianos) a colônia italiana como um todo.

Os descendentes de italianos, influenciados por esse contexto político nacional, por seus próprios e específicos problemas de aceitação na sociedade brasileira como filhos de imigrantes e pelo clima geral de apoio às idéias de extrema direita suscitado pela propaganda italiana, poderiam ter sido cooptados pelos fascios, mas acabaram, dada a sua aculturação e desejo de serem vistos como brasileiros e de participar efetivamente da política brasileira, por aderir à Ação Integralista (vista, por mais de um motivo, como a versão brasileira do Fascismo). Pensando nesse sentido, José Arthur Rios escreveu palavras muito elucidativas a respeito:

Não temos dados que permitam esclarecer em que medida o Integralismo atraiu os italianos. Sendo movimento de características nacionalistas, não devia possuir estrangeiros em suas fileiras. Segundo tudo indica, atraiu número considerável de ítalo-brasileiros, para os quais teria talvez representado uma forma, como outra qualquer, de se ligarem à comunidade brasileira e de se libertarem do complexo de inferioridade que sua condição de marginalidade sempre acarretou. 
Em muitos ítalo-brasileiros, a camisa verde, a saudação "indígena “, a declamação nacionalista, eram a forma de se verem confirmados na comunidade brasileira, de fugirem à instabilidade de cidadãos de duas pátrias. Para outros, porém, perfeitamente assimilados, sem nenhum problema de marginalização, o nome italiano seria mero acidente e sua adesão ao movimento, uma resultante da atmosfera de exaltação nacionalista do meio em que viviam. ${ }^{26}$

O próprio embaixador Cantalupo, aliás, queixava-se a respeito e mostrava algumas ligações entre o interesse da nova geração em participar da política de seu país e a influência do fato de eles serem de origem italiana:

Impressionante é o número de filhos de italianos que aderem ao Integralismo, principalmente, é claro, no Estado de São Paulo e nos Estados meridionais. A meu parecer, eles aderem ao movimento não só porque o mesmo requer fé, energia e entusiasmo, e os filhos de italianos são os únicos brasileiros um tanto enérgicos e entusiastas, mas também porque a amplíssima dosagem de italofilia que Plínio Salgado, com grande habilidade, põe constantemente dentro da propaganda do movimento, evoca nos filhos dos nossos antigos emigrantes, que nós abandonamos completamente por tantas décadas, improvisas e não infecundas saudades sentimentais, e talvez também nacionais, que nos levam a perguntar-nos qual poderia ser hoje a nossa força no Brasil se tivéssemos sabido utilizar em tempo a imensa massa fluida constituída pela italianidade. ${ }^{27}$

Como já dito, nosso eixo analítico central no tocante às bases sociais do Fascismo italiano e do Integralismo no Brasil (e especialmente em São Paulo) concentra-se no grupo onde havia os maiores pontos de cruzamento entre os dois movimentos, ou seja, os italianos e descendentes de italianos. Há sinais, porém, de que, mesmo fora da coletividade italiana e fora de São Paulo, a imensa propaganda fascista foi de grande utilidade para a formação de uma opinião pública mais favorável às idéias de direita, facilitando assim a difusão do Integralismo.

Um indício nesse sentido é levantado nos trabalhos de Hélgio Trindade, quando ele aborda as motivações dos integralistas para a entrada no partido. Depois do anticomunismo, o segundo motivo mais forte de adesão foi a simpatia pelos fascismos europeus. Como não atribuir à propaganda fascista dentro e fora da comunidade italiana boa parte do crédito pela existência deste clima favorável às ideologias de direita?

A propaganda e as atividades fascistas conseguiram dessa maneira criar um clima geral favorável à Itália, ao Fascismo e a Mussolini na comunidade italiana e mesmo fora dela, tendo seu esforço ajudado a levar (ao lado de outros fatores não relacionados à etnia, como a inserção e a luta social dos descendentes de italianos e a problemas regionais próprios ${ }^{28}$ ) muitos ítalo-brasileiros de segunda e 
terceira geração ao Integralismo, o que é um resultado no mínimo curioso (e que pode ser confirmado mesmo em outras comunidades italianas espalhadas pelo Brasil) para a propaganda fascista no território nacional.

Em 1937, Luigi Federzoni, então presidente do Senado Italiano, escreveu um artigo no jornal II Popolo d'Italia no qual, além de comemorar a "força e vivacidade" do Integralismo e a firmeza do presidente Getúlio Vargas, ressaltou justamente essa idéia de que um fator importante na assimilação de idéias fascistas pelo Integralismo e na criação de um sentimento de apoio difuso às ideologias de direita no Brasil foi a atividade do Fascismo italiano no Brasil e, em especial, em São Paulo:

De fato, é certo que um importante fator para a ascensão (...) do Integralismo foi fornecida pela atividade dos nossos fascistas, os quais, no Brasil e em todo lugar, constituem centros vitais dentro das comunidades italianas(.) É um fato que nossos fasci, nossa imprensa e nossas escolas ajudaram a criar uma nova mentalidade naquela nação, onde os italianos representam uma formidável contribuição de trabalho e intelecto. De fato, vários dos jovens líderes do Integralismo, conhecidos por sua cultura e valor moral, são filhos de italianos e foram educados em nossa esplêndida Dante Alighieri e vários dos mártires camisa verde que caíram em defesa da causa eram de origem italiana.

Eu devo acrescentar que em nenhuma das nações sul americanas que eu visitei, eu encontrei um conhecimento tão acurado e profundo, uma compreensão tão cordial e penetrante da história do Fascismo e do pensamento e trabalho de Mussolini.29

Reconhecer essa importância do Fascismo italiano como suporte para o desenvolvimento do Integralismo (e também do regime varguista) não significa esquecer outras influências externas (especialmente do Estado Novo português e do Nazismo alemão) dentro do Integralismo, as suas especificidades dentro do conjunto dos movimentos fascistas, e nem propor que ele só se desenvolveu como reflexo de algo externo. O reconhecimento dessa influência e dos precisos canais pelos quais ela se transmitiu nos permite, porém, não só ampliar o debate clássico sobre a natureza do movimento através da inserção de novos elementos (existência de solidariedade ideológica, contatos e relacionamento mútuo em nível de cúpula e de base, etc.), como verificar o grau de aprofundamento dos ideais fascistas na sociedade brasileira do entre-guerras e o papel das potências fascistas e seus interesses estratégicos nesse processo, o que é uma tarefa fundamental.

CONCLUSÃO 
Entre as duas guerras mundiais, o Fascismo realizou um intenso esforço para reconectar os imigrantes e seus filhos espalhados pelo mundo com a Itália, e espalhar a ideologia fascista entre eles. Nesse esforço, o Fascismo se baseou nos velhos debates da Itália liberal relacionados a eles e ao seu uso como instrumento de poder italiano dentro da luta imperialista global. Através, especialmente, da mediação dos nacionalistas, o regime de Mussolini reelaborou, de fato, a antiga discussão em termos fascistas (associando "italianidade" com "Fascismo"), mas mantendo como linha geral a diretriz de utilizar as comunidades italianas do exterior como fatores e ferramentas da política externa italiana.

Um reflexo dessa política foi uma potencialização maciça dos antigos mecanismos que o Estado italiano tradicionalmente já havia utilizado para manter contato com seus emigrados e a criação de outros, mais diretamente relacionados com a ideologia e o estilo fascista, no exterior. Nesse sentido, buscou-se o controle sobre os antigos mecanismos de socialização (associações, imprensa, escolas) dos emigrados italianos em todo o mundo e a implantação de outros (os fasci all'estero, os Dopolavoro, as Casa d'Italia) especificadamente fascistas.

O Brasil não ficou imune a essas transformações da política do Estado italiano com relação a seus emigrantes, os quais foram convertidos em instrumen98 tos privilegiados nas relações Brasil-Itália. Nesse sentido, as coletividades italianas do Brasil e, especialmente, as de São Paulo, foram particularmente atingidas pelo esforço fascista de reconexão dos antigos emigrantes e seus filhos com a Itália, que procurou transformá-las em componentes-chave da ativa política italiana dirigida ao Brasil no entre-guerras.

No tocante à receptividade dos italianos do Brasil à propaganda fascista, é patente que ela foi muito variável em intensidade e que também oscilou fortemente segundo critérios sociais, geracionais, regionais e outros. Nesse sentido, é evidente uma forte popularidade do regime e da ideologia fascista entre os italianos natos e pertencentes às classes burguesas e médias das colônias (e, em especial, a de São Paulo), enquanto o grosso dos trabalhadores urbanos e rurais e os filhos de italianos manifestaram uma certa simpatia pelo Fascismo (normalmente mediada pelo resgate do orgulho da origem italiana que a ativíssima política externa do Fascismo proporcionava), mas sem uma adesão direta. Variações regionais e temporais também estiveram presentes, assim como foi importante para a popularização do Fascismo entre os imigrantes e seus filhos a fraqueza do antifascismo italiano com base no país e a própria popularidade fascista entre os brasileiros.

Além dos seus efeitos evidentes dentro da coletividade italiana, a ação do Fascismo e do antifascismo italianos no Brasil teve conseqüências de importân- 
cia também para a sociedade que hospedava tais imigrantes. De fato, as tensões surgidas na colisão do nacionalismo italiano e do brasileiro, a intensa batalha de propaganda travada pelas grandes potências no Brasil dos anos 30, e vários outros pontos demonstram que a questão do Fascismo italiano no Brasil nunca foi restrita às fronteiras da comunidade italiana e nem mesmo, na realidade, às fronteiras brasileiras, sendo sempre uma problemática completamente transnacional.

Essa perspectiva transnacional nos permite colocar em perspectiva a experiência do Fascismo italiano no Brasil e entendê-la não como uma realidade estanque, mas como inserida numa teia que atingia proporções globais, e que só assim pode ser compreendida. A tão falada globalização não é, portanto, algo específico deste fim de século, e o estudo da experiência do Fascismo e do antifascismo italianos no Brasil apenas confirma como a história do Brasil tem que ser vista a partir da consciência dos contextos maiores em que ela se insere. Sem isso, a nossa visão da realidade será sempre parcial e fora de perspectiva, e as possíveis colaborações dos historiadores para o entendimento desta realidade serão inevitavelmente prejudicadas.

É fazendo a conexão do Brasil com o mundo que passamos a ser capazes, assim, de delimitar melhor a realidade política brasileira do entre-guerras, compreendendo o papel das ações do Fascismo italiano no desenvolvimento do pensamento e da ação política da direita nacional.

A ação fascista no País (seja a voltada para os italianos e seus filhos, seja a voltada para os brasileiros) foi muito útil, realmente, à direita nacional ao popularizar as idéias autoritárias e estimular muitas pessoas a uma maior simpatia em relação ao Estado Novo e ao Integralismo. Dentro das coletividades italianas o mesmo ocorreu, com o intenso relacionamento dos fascistas italianos com os integralistas e a propaganda italiana levando, ao lado de outros fatores além etnia, muitos filhos de italianos (basicamente, mas não só os oriundos das classes médias), a militarem diretamente nas hostes integralistas e muitos outros (especialmente aqueles apenas levemente conquistados pelo Fascismo) a simpatizarem com o mesmo. O esforço fascista de controlar totalmente as mentes e as almas dos italianos e seus filhos residentes no Brasil não foi, assim, coroado de êxito, mas colaborou decisivamente para o reforço da cultura política de direita no Brasil do período e isso deve ser ressaltado.

Aos fascistas italianos coube, dessa forma, um papel importante na guinada à direita da sociedade brasileira no entre-guerras, o que talvez ajude a explicar os caminhos políticos da sociedade brasileira também nas décadas posteriores ao fim do Fascismo na Itália.

Esse "talvez" no último parágrafo não é ocasional. De fato, dentre os inúmeros caminhos de pesquisa que este trabalho sugere, o mais relevante seria um 
estudo de fôlego sobre o pensamento de direita brasileiro em todo o século XX, rompendo os limites cronológicos dos anos 20 e 30.

Realmente, o que ficou evidente neste texto é o papel fundamental do referencial externo na política nacional do entre-guerras. É impossível prever se nós teríamos tido o Integralismo ou o Estado Novo, por exemplo, sem esse referencial externo, mas é certo que estes movimentos teriam tido características bem diferentes sem ele ${ }^{30}$.

Só saindo, contudo, desse quadro limitado e passando pelos mais diferentes contextos (a República Velha, a era Vargas, o período populista, o regime militar), é que poderíamos acompanhar o que a direita nacional absorveu dos Fascismos europeus e o que é realmente específico dela e das tradições autoritárias, racistas e de exclusão social da sociedade brasileira. Num momento em que tanto se debate sobre os conceitos de "direita" e de "esquerda" em nível teórico, e em que estes parecem perder suas identidades, só teríamos a ganhar com um trabalho desse tipo, necessário também para um conhecimento maior da própria cultura política brasileira.

\section{NOTAS}

* O presente artigo é derivado do capítulo final da tese de doutorado defendida em dezembro de 1998 no Departamento de História da UNICAMP sob o título Sob o Signo do fascio: o Fascismo, os imigrantes italianos e o brasil, 1922-1943. Ele foi publicado anteriormente, numa versão muito reduzida, em inglês e voltada para um público não-brasileiro. A presente versão amplia substancialmente as reflexões lá esboçadas. Ver, para o texto em inglês, "Between Sigma na Fascio. $\mathrm{Na}$ analysis of the relationship between Italian Fascism na Brazilian Integralism.". In Luso Brazilian Review. Vol. XXXVII, n 1, pp. 93-105, 2000.

${ }^{1}$ Vide TRINDADE, Hélgio. Integralismo - O Fascismo brasileiro na década de 30. São Paulo: Difel, 1974 e "Integralismo: Teoria e práxis política nos anos 30.” In FAUSTO, Bóris. História Geral da Civilização Brasileira. Tomo III, volume 3, São Paulo, 1981, pp. 297-336; LEV1NE, Robert. O regime de Vargas. Os anos críticos, 1934-1938. Rio de Janeiro: Nova Fronteira, 1978, pp. 129-156; VASCONCELLOS, Gilberto. Ideologia Curupira - Análise do discurso Integralista. São Paulo, 1979; CHAS1N, José. O Integralismo de Plínio Salgado - Forma de regressividade do capitalismo hiper tardia São Paulo, 1978 e CHAUI, Marilena. "Apontamentos para uma crítica à Ação Integralista Brasileira” In CHAUI, Marilena e FRANCO, Maria Sílvia Carvalho. Ideologia e mobilização popular. Rio de Janeiro: Paz e Terra, 1978.

${ }^{2}$ As informações a seguir vêm basicamente de TRENTO, Angelo. "Relações entre Fascismo e Integralismo: o ponto de vista do Ministério das Relações Exteriores italiano". In Ciência e Cultura, XXXIV, 12, pp. 1.601-1.613, 1982. Vide também SEITENFUS, Ricardo. O Brasil de Getúlio Vargas e a formação dos blocos - O processo de envolvimento brasileiro na II Guerra Mundial. São Paulo: Cia Editora Nacional, 1985, e "Quatro teses sobre a política externa brasileira nos anos 30". In ALBUQUERQUE, José Augusto Guilhon. Sessenta anos de política externa brasileira, 1930-1990 - Crescimento, modernização e política externa. Vol. 1, São Paulo: NUPRI-USP/Cultura Editores Associados, 1996, pp. 115-160 e BERTONHA, João Fábio. “O Brasil, os imigrantes italianos e a política externa fascista (1922-1942).” In Revista Brasileira de Política Internacional. Brasília, 40, 2. pp. 106-130, 1997. 
${ }^{3} \mathrm{Um}$ dos portadores do dinheiro italiano para os integralistas, aliás, era o conhecido militante fascista italiano e morador de São Paulo Nunzio Greco. Vide a sua entrevista no jornal O Globo de 27/5/1946 confirmando o fato e citada em Archivio Stonco del Ministero degli Affari Esten (ASMAE)/Affari Politici 1946-1950. (Brasile), b. 1, p. "Stampa - Brasile, 1946".

Para os possíveis incrédulos sobre essa operação (o que deve incluir boa parte dos ex-integralistas e simpatizantes), ver as pastas sobre o Integralismo no arquivo supracitado e, especialmente, b. 16, p. "Integralismo - 1938", onde consta uma promissória de 100 contos de réis, assinada pessoalmente por Plínio Salgado.

${ }^{4}$ CARONE, Edgar. A República Nova. 1930-1937. São Paulo: DIFEL, 1974, pp. 194-195.

${ }^{5}$ Que se originava também, sem dúvida, da enorme quantidade de bibliografia sobre o Fascismo que circulava no País naqueles anos, e do imenso volume de propaganda que o governo fascista despejava no Brasil nos anos 30 e que atingia também os integralistas. Em 1935, por exemplo, o MinCulPop distribuiu grande quantidade de livros sobre a doutrina fascista para líderes da AIB como Gustavo Barroso, Miguel Reale, Jeová Motta e Olbiano de Mello. Vide Archivio Centrale dello Stato/Minístero della Cultura Popolare, Divisione Generale di Propaganda (ACS/MinCulPop, DGP), b. 272, f. 10, sottof. 30, p. "Invio di pubblicazioni nel Brasile", Informe MinCulPop, 21/3/1935.

Registros sobre fornecimento maciço de material de propaganda e sobre a doutrina fascista italiana para bibliotecas, centros de estudo e simples militantes integralistas também são abundantes nesse arquivo.

${ }^{6}$ Ver REALE, Miguel. Memórias. São Paulo: Saraiva,: 1987. A Reale era atribuído, pelo governo italiano, um papel-chave para a penetração e o desenvolvimento da influência fascista no Integralismo, dada a sua origem italiana e admiração pelo Duce e pelo Fascismo. Vide Relatório do Encarregado de Negócios Menzinger de 19/10/1936 in ASMAE/Affari Politici 1931-1945 (Brasile), b. 16. Reale também se refugiou na Itália após o fracassado golpe integralista e foi muito bem recebido. Vide ACS/Divisione Generale di Pubblica Sicurezza (DGPS), Div. Affari Generali e riservati, 1939, b. 1/J, "Brasile - Notizie", diversos documentos. Para o envio, por Reale, de livros com dedicatórias a Mussolini, ainda em 1939, ver ASMAE/Affari Politici 1931-1945 (Brasile), b. 15, Informe do Ministero degli Affari Esteri, 28/1/1939.

${ }^{7}$ Vide anúncio a respeito em II Pasquino Coloniale, 16/3/1932. Ferruccio Rubbiani também foi fundador de uma editora em São Paulo chamada Sociedade Editora Latina, que durou pouco, mas cuja primeira publicação foi, não casualmente, Como eu vi a Itália, de Plínio Salgado. Ver TRENTO, Ângelo. Do outro lado do Atlântico - Um século de imigração italiana no Brasil, São Paulo: Instituto Italiano de Cultura/Nobel, 1989, p. 299.

Essas atividades e publicações, curiosamente, não estão registradas nem na bibliografia oficial de Plínio Salgado e nem em seu arquivo pessoal. Também seus contatos com fascistas e nazistas quando do exílio em Portugal não são mencionados em suas memórias do período e nem em seus papéis. Um caso claro de construção da memória. Ver SALGADO, Plínio. Tempo de exílio. São Paulo: Voz do Oeste, 1980, e seu arquivo pessoal depositado no Arquivo Municipal de Rio Claro/SP.

${ }^{8}$ Para esses acontecimentos, vide CARONE, Edgar. Op. cit., 1973, pp. 299-305; TRINDADE, Hélgio. Op. cit. p. 100, Arquivo Diplomático Americano (ADA), Rolo 2/380, código 832.00, fotograma 1.041, e ASMAE/Affari Politici 1931-1945 (Brasile), b. 14, p. "Onoreficienze ed Onoranze", f. 3, Informe Consulado de São Paulo, 24/4/1937 e b. 11, f.9, Relatório Embaixada italiana de 3/7/1937.

${ }^{9}$ LECHLER, Pfaner. "Der Integralismus in Brasilien". In Der Deutsche Auswanderer. Citado em TRINDADE, Hélgio. Op. cit. p. 43.

${ }^{10}$ SALGADO, Plínio. O Estrangeiro. São Paulo, 1926, pp. 174-175.

${ }^{11}$ As duas citações vêm, respectivamente, de ACS/MinCuIPop, DGP, b. 277, p. "Collettività italiane 
nello Stato di Santa Catarina", relatório de Guido Zecchin ao MAE, 31/5/1935, e ASMAE/Affari Politicí 193 1-1945 (Brasile), b. 6, f. 8, relatório do Embaixador Cantalupo de 9/3/1935.

${ }^{12}$ Para o caso do relacionamento entre nazistas e integralistas, que também oscilou entre conflito e colaboração, mas que parece ter sido menos harmonioso, vide GERTZ, Renè. O Fascismo no Sul do Brasil - Germanismo, Nazismo, Integralismo. Porto Alegre: Mercado Aberto, 1987. O mesmo livro aborda a questão da presença dos descendentes de alemães no Integralismo.

${ }^{13}$ Para essas informações, vide Arquivo do Estado de São Paulo/Delegacia de Ordem Política e Social (AESP/DOPS), Prontuário 29293 (“Opera Nazionale Dopolavoro”), relatório de 30/5/1939 e ACS/DGPS, Divisione Affari Generali e riservati, 1939, b. 1/J, p. "Brasile - Notizie", informe MAE 5/8/1938.

${ }^{14}$ Vide, por exemplo, a carta do integralista João de Freitas, de Barra do Piraí/RJ a Mussolini, em 1/9/1936, na qual ele não só se mostrava admirador da Itália fascista e pedia "uma foto do Duce para colocar ao lado da de Plínio Salgado", como admitia ter aprendido muito sobre o Fascismo com um amigo italiano, o camisa-negra Carmine Montuori. Ver ASMAE/Affari Politici 1931-1945 (Brasile), b. 9 , f. 2 .

${ }^{15}$ Ver o depoimento do senhor Antônio, filho de italianos e integralista que discursou no Dopolavoro de Sorocaba em 1934, em BOSI, Ecléa. Memória e Sociedade - Lembranças de Velhos. São Paulo: T. A. Queiroz, 1987, p. 188, e AESP/DOPS, Prontuário 29.293 (“Opera Nazionale Dopolavoro”), relatório de 19/9/1940, no qual um depoente, filho de italianos, afirmava freqüentar sem problemas rodas fascistas e integralistas. Os integralistas realizavam atividades conjuntas também com os nazistas e com os falangistas espanhóis presentes no Brasil, o que ressalta sua identificação com o Fascismo internacional.

$102{ }^{16} \mathrm{O}$ Arquivo Edgar Leuenroth/UNICAMP conserva uma coleção de livros que pertenceu a um italiano que vivia em Jundiaí/SP nos anos 30, na qual livros fascistas italianos (inclusive com carimbos de doação do governo italiano e do fascio de Jundiaí) convivem com farta bibliografia integralista, o que parece indicar que a propaganda dos dois movimentos se cruzava e se interpunha regularmente em nível de base. Para outras informações no mesmo sentido, ver TUCCI CARNEIRO, Maria Luísa. Livros proibidos, idéias malditas. O DEOPS e as minorias silenciadas. São Paulo: Estação Liberdade, 1997, p. 44.

${ }^{17}$ Vide, por exemplo, o livro de atas do núcleo integralista de Rio Claro/SP (disponível no Museu da Cidade), que revela que diversas das reuniões do núcleo aconteceram na sede da Sociedade italiana local e a reunião conjunta integralista/fascista na Sociedade italiana Vittorio Veneto em Tambaú (SP) em 15/3/1937, com calorosas manifestações de apreço mútuo, registrada em AESP/DOPS, Prontuário 40.499 (“Ação Integralista Brasileira”). Ver também a cessão da sala "Marina Crespi” do Circolo Italiano de São Paulo à Ação Integralista, mencionada em AESP/DOPS, Prontuário 40.632 ("Circolo Italiano de São Paulo"), relatório de 28/6/1945.

$\mathrm{O}$ uso de associações italianas para manifestações integralistas ficou tão evidente em certo momento que Menotti del Picchia afirmou ter se dirigido ao cônsul Giuseppe Castruccio com um pedido para que isso não ocorresse mais, dados os óbvios inconvenientes dessa visibilidade. Vide AESP/DOPS, Prontuário 613 (“Cesar Rivelli”), depoimento de Menotti del Picchia de 24/5/1938.

${ }^{18}$ Vide SCARANO, Júlia Maria Leonor. "Considerações Preliminares sobre uma cidade de imigração teuto-italiana e os efeitos do Segundo Conflito Mundial.” In Colonização e Migração - Anais do IV Simpósio Nacional dos Professores Universitários de História. São Paulo, 1969, pp.507-532 e 517.

${ }^{19}$ Para um artigo que faz reflexões gerais sobre essa dicotomia dentro do universo fascista, ver BERTONHA, João Fábio. “A Questão da "Internacional Fascista” no mundo das relações internacionais: 
a extrema direita entre solidariedade ideológica e rivalidade nacionalista." In Revista Brasileira de Política Internacional, Brasília, 43, 2000, pp. 99-118.

${ }^{20} \mathrm{O}$ único lugar onde houve uma divisão mais séria entre fascistas e integralistas foi o Rio Grande do Sul, mas por problemas de política local e não por incompatibilidade ideológica. Ver BERTONHA, João Fábio. "Entre a bombacha e a camisa negra: notas sobre a ação do Fascismo italiano e do Integralismo no Rio Grande do Sul.” In Estudos Ibero-Americanos. Porto Alegre, 2, 1998, pp. $247-$ 268.

${ }^{21}$ Os integralistas comemoraram, por exemplo, a vitória dos italianos na Guerra da Abissínia em 1936. Vide os jornais integralistas da época e a carta do integralista Alberto Cotrin Duarte a Ettore Giorno em 1936, cheia de júbilo pela vitória da "idéia fascista" in ACS/MinCu1Pop, DGP, b. 273, f. 10, sottof. 4, p. "Invio di pubblicazioni di propaganda nel Brasile". Para urna demonstração de como isso ocorria até em pequenas comunidades italianas no interior de São Paulo, vide a comemoração conjunta de integralistas e fascistas italianos pela criação do Império italiano em Capivari/SP em 1936, em DE ALMEIDA Jr., Aprígio. 1936 - A comunidade italiana de Capivari entre o fascio e o sigma, Piracicaba: UN1MEP, 1997, mimeo, vários momentos.

${ }^{22}$ ASMAE/Affari Politici 1931-1945 (Brasile), b. 16, ti Y2, relatório do Encarregado de Negócios Menzinger, 19/10/1936

${ }^{23}$ Idem, b. 15, p. "Integralismo - Rifugiati politici"1/2", relatório de 18/3/1937. Convém ressaltar que, como ficou evidente, essa divisão era muito fluida e certamente existiam pessoas que combinavam as duas militâncias. Ela estava, ainda assim, presente. Tanto que é possível verificar que os italianos que militavam nos fasci eram normalmente apenas simpatizantes do Integralismo, enquanto os filhos de italianos pertencentes à AIB podiam até comparecer à cerimônias conjuntas e admirar profundamente o Duce e a Itália, mas sem nunca esquecer que eram, acima de tudo, brasileiros e integralistas.

${ }^{24}$ GERTZ, Renè. op. cit., p. 118 e seguintes; "Preconceitos de sangue.” In História: Questões e debates. Curitiba, X, 18/19, pp. 157-190, 1989.

${ }^{25} \mathrm{O}$ fato da maioria desses filhos de imigrantes - que queriam ser aceitos plenamente como brasileiros através da militância no Integralismo e que eram simpáticos ao Fascismo ou ao Nazismo também por origem étnica - ser constituída de membros das classes médias desejosos de representação política e preocupados com a ordem social do País, apenas ressalta como as questões étnicas se conectam com as de classe.

${ }^{26}$ RIOS, José Arthur. Op. cit., 1959, pp. 64-65.

${ }^{27}$ ASMAE/Affari Politici 193 1-1945 (Brasile), b. 6, p. “Brasile - Rapporti politici - 1934”, relatório do Embaixador Cantalupo, 1/10/1934.

${ }^{28}$ Os casos do Espírito Santo, Santa Catarina e Rio Grande do Sul são, nesse sentido, exemplares, pois a imensa penetração do Integralismo entre os descendentes de italianos nessas regiões derivou não só de razões de classe (receio dos pequenos proprietários rurais diante da socialização das terras teoricamente defendida pela esquerda) e étnicas (descendentes de italianos que admiravam o Fascismo e estavam sob forte influência da Igreja Católica e que eram, por isso, simpáticos à AIB), como a outras de ordem local, de luta contra as elites estaduais. O fato de alguns desses elementos (a força da Igreja, a luta contra a elite tradicional) não estarem presentes no contexto paulista ajuda a explicar porque, em termos percentuais, existiam mais descendentes de italianos integralistas no extremo sul do País do que em São Paulo.

${ }^{29}$ Não tivemos acesso ao artigo original do jornal, de 13/11/1937. Uma transcrição se encontra no 
relatório da Embaixada dos Estados Unidos em Roma ao Depto de Estado de 18/11/1937. Vide ADA, Rolo 3/380, Código 832.00, fotograma 1.114.

${ }^{30} \mathrm{O}$ que não quer dizer, note-se, que concordemos com as interpretações que identificam no Varguismo um tipo de Fascismo. Apenas consideramos que os construtores do Estado Novo não deixaram de ter um olhar voltado para o que ocorria na Europa e se utilizaram das experiências e informações que vinham de lá, sem que isso implicasse a construção de um Estado do tipo totalitário ou mesmo fascista no Brasil.

Artigo recebido em 12/1999. Aprovado em 09/2000. 